\title{
The effects of habitat fragmentation due to forestry plantation establishment on the demography and genetic variation of a marsupial carnivore, Antechinus agilis
}

\author{
S.C. Banks ${ }^{\text {a,* }}$, G.R. Finlayson ${ }^{\text {a }}$, S.J. Lawson ${ }^{\text {b }}$, D.B. Lindenmayer ${ }^{\text {b }}$, \\ D. Paetkau ${ }^{\mathrm{c}, \mathrm{d}}$, S.J. Ward ${ }^{\mathrm{e}}$, A.C. Taylor ${ }^{\mathrm{a}}$ \\ a Australian Centre for Biodiversity: Analysis, Policy and Management, School of Biological Sciences, \\ Monash University, Melbourne, VIC 3800, Australia \\ ${ }^{\mathrm{b}}$ Centre for Resource and Environmental Studies, The Australian National University, Canberra, ACT 0200, Australia \\ ${ }^{\mathrm{c}}$ Department of Zoology and Entomology, University of Queensland, St. Lucia, QLD 4072, Australia \\ ${ }^{\mathrm{d}}$ Wildlife Genetics International, P.O. Box 274, Nelson, Canada \\ ${ }^{\mathrm{e}}$ Department of Zoology, The University of Melbourne, VIC 3010, Australia
}

Received 22 June 2004

\begin{abstract}
We conducted a demographic and genetic study to investigate the effects of fragmentation due to the establishment of an exotic softwood plantation on populations of a small marsupial carnivore, the agile antechinus (Antechinus agilis), and the factors influencing the persistence of those populations in the fragmented habitat. The first aspect of the study was a descriptive analysis of patch occupancy and population size, in which we found a patch occupancy rate of $70 \%$ among 23 sites in the fragmented habitat compared to $100 \%$ among 48 sites with the same habitat characteristics in unfragmented habitat. Mark-recapture analyses yielded most-likely population size estimates of between 3 and 85 among the 16 occupied patches in the fragmented habitat. Hierarchical partitioning and model selection were used to identify geographic and habitat-related characteristics that influence patch occupancy and population size. Patch occupancy was primarily influenced by geographic isolation and habitat quality (vegetation basal area). The variance in population size among occupied sites was influenced primarily by forest type (dominant Eucalyptus species) and, to a lesser extent, by patch area and topographic context (gully sites had larger populations). A comparison of the sex ratios between the samples from the two habitat contexts revealed a significant deficiency of males in the fragmented habitat. We hypothesise that this is due to male-biased dispersal in an environment with increased dispersal-associated mortality. The population size and sex ratio data were incorporated into a simulation study to estimate the proportion of genetic diversity that would have been lost over the known timescale since fragmentation if the patch populations had been totally isolated. The observed difference in genetic diversity (gene diversity and allelic richness at microsatellite and mitochondrial markers) between 16 fragmented and 12 unfragmented sites was extremely low and inconsistent with the isolation of the patch populations. Our results show that although the remnant habitat patches comprise approximately $2 \%$ of the study area, they can support non-isolated populations. However, the distribution of agile antechinus populations in the fragmented system is dependent on habitat quality and patch connectivity. (c) 2004 Elsevier Ltd. All rights reserved.
\end{abstract}

\footnotetext{
* Corresponding author. Tel.: +61 39905 5661; fax: +61 399055613.

E-mail address: sam.banks@sci.monash.edu.au (S.C. Banks).
} 


\section{Introduction}

The value of remnant or restored patches of habitat within production landscapes has been a major focus of conservation biology over recent decades (Saunders et al., 1993; Craig et al., 2000). Agriculture and forestry activities dominate many landscapes and the retention of patches of habitat for native species provides an opportunity to preserve biodiversity in such areas (Lindenmayer and Franklin, 2002). However, the long-term persistence of populations surviving in fragmented habitats is compromised by a variety of factors that can be broadly grouped into three categories relating to the amount of available habitat, the quality of that habitat, and population connectivity. Species richness and individual abundance are predicted to decrease with reduced patch size (MacArthur and Wilson, 1963). This prediction has been supported by several observational and experimental studies (e.g., Dunstan and Fox, 1996; Fahrig, 2001) but the effects of patch size on ecological communities have varied between landscapes, habitat contexts and taxa (Debinski and Holt, 2000). Habitat quality has been shown to be an important factor influencing the persistence of species in fragmented habitats (Bentley et al., 2000; Knight and Fox, 2000). For instance, whether the marsupial carnivore Antechinus stuartii was present in particular remnant habitat patches in a fragmented landscape was found to be most strongly influenced by habitat structure, which was in turn influenced by habitat area and the degree of human-induced disturbance to the patch (Knight and Fox, 2000). Fragmentation may also affect habitat quality by the 'edge effect', whereby habitats are increasingly affected by exotic species and altered climatic conditions at patch boundaries (Saunders et al., 1991). Finally, the connectivity of populations in fragmented habitats is a major influence on their probability of persistence (Stacey and Taper, 1992). The properties of the matrix (Ricketts, 2001; Stow et al., 2001), the presence of habitat corridors (Mech and Hallett, 2001) and the dispersal capabilities of the species in question (Brouat et al., 2003; Driscoll, 2004) may influence patterns of migration in fragmented habitats.

In Australia, the majority of habitat clearing has occurred for agriculture (State of the Environment Advisory Council, 2001), although a small but increasing proportion of the rural landscape is dedicated to forestry plantations, most commonly of exotic conifers such as Pinus radiata. Exotic pine plantations currently cover approximately 1 million ha in Australia and this area is expected to increase threefold over the next two decades (Department of Primary Industries and Energy, 1997) so understanding how to conserve native biodiversity in plantation landscapes is an increasingly important issue. Many native Australian animal species are rare or absent in pine plantations but may be present in remnant patches of native vegetation within the plantations (Lindenmayer et al., 1999). Preservation of these remnants therefore presents an opportunity for conserving wildlife in plantation landscapes. However, the value of retaining these remnants as a strategy to conserve wildlife populations that are viable in the long term is unknown. Ecological and genetic studies that provide data on the environmental factors influencing the distribution and viability of wildlife populations are therefore crucial for better conservation planning.

In this study, we use a demographic and genetic approach to investigate the effects of fragmentation due to establishment of a plantation of exotic $P$. radiata at Tumut (New South Wales, Australia) on the distribution (patch occupancy, population size and sex ratio) and connectivity of populations of a small marsupial carnivore, the agile antechinus (Antechinus agilis). Although the demographic and genetic response of populations to fragmentation are temporally dependent (Steinberg and Jordan, 1997; Debinski and Holt, 2000), we expected that any negative impacts of fragmentation would be evident over the timescale for which the study are has been fragmented (40-50 generations). A previous survey found that although $A$. agilis was very rare in the plantation itself, the species was often found in remnant patches of eucalypt forest within the plantation (Lindenmayer et al., 1999). Little is known about the demography of these populations, including parameters such as population size, sex ratio and their degree of isolation, or the environmental variables influencing these parameters in the plantation system. Their persistence could be due to dispersal through the pine plantation matrix or to large population sizes that are relatively resistant to localised extinction (Lindenmayer et al., 1999). Two studies have since used population viability analysis (PVA) to attempt to predict the probability of patch occupancy by $A$. agilis for a subset of the sites studied by Lindenmayer et al. (1999), Lindenmayer and Lacy (2001) and Ball et al. (2003). The species studied is one of the most commonly studied and wellknown marsupials and the PVA models used a range of habitat and dispersal scenarios thought to encompass the majority of plausible situations. Despite this, the PVA models in both studies performed poorly for $A$. agilis, being unable to predict accurately the observed patterns of site occupancy. Although much is known about the ecology of $A$. agilis in unfragmented habitats, these modelling studies show that the effects of habitat fragmentation on the demography of even common and well-studied species are very poorly understood.

Here, we compare patterns of site occupancy between unfragmented habitat and eucalypt patches within the pine plantation, and use hierarchical partitioning (Chevan and Sutherland, 1991) and a model selection approach (Fleishman et al., 2004) to identify habitat characteristics that influence patch occupancy in the 
fragmented system. We then use a mark-recapture approach to estimate population size in the occupied patches in the fragmented system and determine what habitat characteristics explain the observed variation in abundance between patches. Thirdly, we compare sex ratios between the sites in the different habitat contexts, as several studies (including an earlier one of $A$. agilis by Downes et al., 1997) have noted that sex ratios in fragmented habitats may differ from those in unfragmented habitat (Raska-Jurgiel, 1992; Beshkarev et al., 1995). Lastly, we address the issue of whether fragmentation has increased the degree of isolation of $A$. agilis populations surviving in remnant habitat patches in the pine plantation. If these populations were simply isolated remnants of the species' pre-fragmentation distribution, we would expect them to display reduced genetic diversity due to genetic drift and inbreeding. Since small, isolated populations will lose genetic variation at a rate proportional to their effective population size, we incorporate demographic data into a simulation analysis to determine what level of loss of genetic variation would be expected if these populations were isolated and compare the observed genetic diversity data to these expectations. Even if fragmentation had not completely isolated these populations but had significantly reduced connectivity we might expect to observe a reduction in genetic diversity at these sites proportional to the population size or their geographic isolation. Recent studies have shown that fragmentation may have differing effects on dispersal patterns in males and females, so the effects on genetic diversity at nuclear and mitochondrial loci may differ under sex-biased dispersal (Stow et al., 2001; Tallmon et al., 2002). Consequently, we used data from both nuclear (microsatellite) and mitochondrial (control region sequence) loci in our analyses.

\section{Methods}

\subsection{Study species}

The agile antechinus is a small dasyurid marsupial (males 20-45 g, females 14-25 g) that was formally described in 1998 when the brown antechinus (A. stuartii) was recognised as a species-complex incorporating a range of taxa occupying largely non-overlapping distributions (Dickman et al., 1998; Sumner and Dickman, 1998; Crowther et al., 2003). Based on study location, the species referred to as $A$. stuartii in some work cited here is more likely to have been $A$. agilis. The species studied here was identified as $A$. agilis by comparing the sequence of 780 base pairs (bp) of the mitochondrial cytochrome $b$ gene of 297 animals sampled at Tumut to sequences from known $A$. agilis and $A$. stuartii (S. Banks, unpublished data).
The diet of $A$. agilis consists primarily of insects and spiders (Lunney et al., 2001). Individuals are born in September and are weaned after 3-4 months. The mating season occurs in August at Tumut, and females typically have $8-10$ pouch young. Multiple paternity is common, with most litters being sired by two or three males (Kraaijevelt-Smit et al., 2002a). All males die immediately after the mating season, although some females may survive to breed in a second year. Individuals forage predominantly on the ground and nest communally, usually in tree hollows. Post-natal dispersal is male-biased and individuals may continue to move between communal nests prior to the breeding season (Cockburn and Lazenby-Cohen, 1992).

\subsection{Study area}

The study was conducted in Buccleuch State Forest near Tumut, New South Wales, Australia $\left(148^{\circ} 40^{\prime} \mathrm{E}\right.$, $35^{\circ} 10^{\prime} \mathrm{S}$, Fig. 1). The forest consists of approximately 50,000 ha of exotic $P$. radiata plantation, within which there are 192 areas of remnant Eucalyptus forest (Lindenmayer et al., 1999). Twenty-three remnant sites were studied, comprising all patches within an approximately $8 \mathrm{~km} \times 7 \mathrm{~km}$ sub-section of the pine plantation (Fig. 2), and these ranged in altitude from approximately 850 $1100 \mathrm{~m}$. These patches ranged in size from approximately $0.1-62$ ha and the year in which the surrounding eucalypt forest was cleared and converted to pine plantation is known. The forest within these remnants is dominated by different eucalypt species including Eucalyptus radiata, E. viminalis, E. dalrympleana, E. pauciflora, E. camphora, E. dives, E. bridgesiana, $E$. fastigata and E. macrorhyncha. Understorey vegetation is dominated by Acacia dealbata, A. melanoxylon, Exocarpos cupressiformis, Leptospermum juniperinium, Cassinia spp., ferns including Polystichum proliferum, Pteridium esculentum and Blechnum nudum and grasses

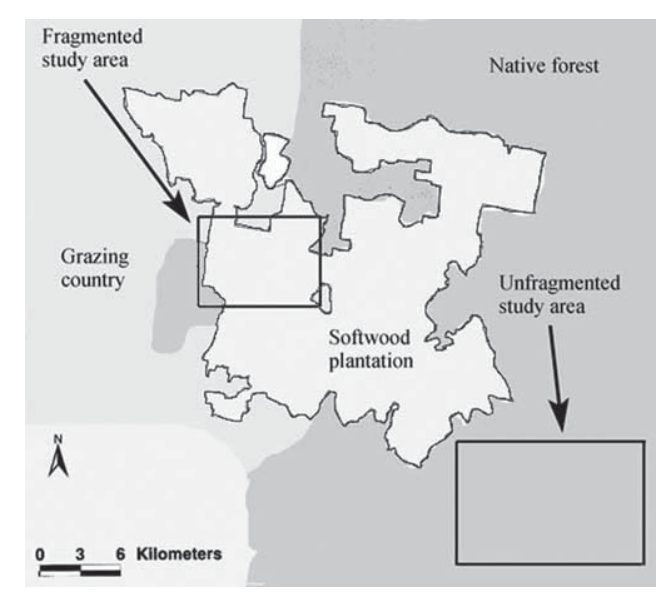

Fig. 1. Map showing the location of the study areas in the pine plantation and unfragmented eucalypt forest. 


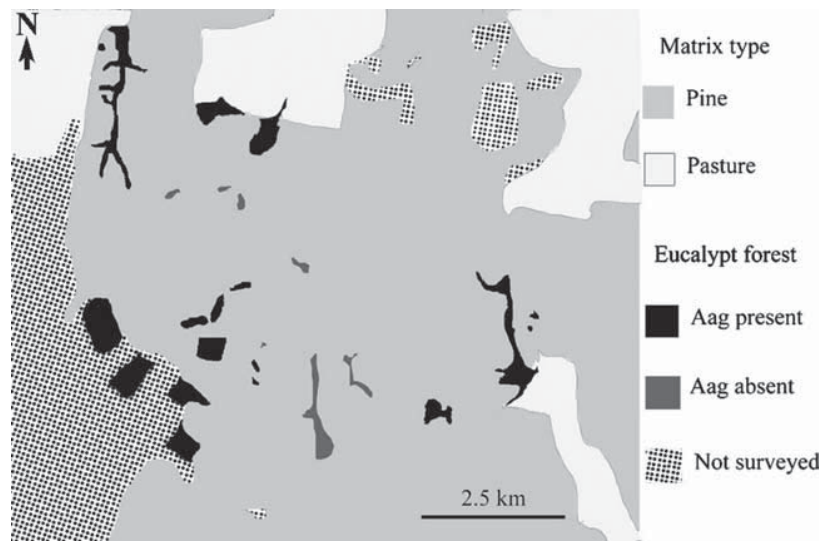

Fig. 2. Map showing the location and occupancy by Antechinus agilis of fragmented sites (two occupied sites are not shown and are to the east of the map boundary). The four occupied sites in eucalypt forest to the west of the pine plantation were not included among the fragmented sites.

of the genus Poa. The exotic blackberry (Rubus fructico$s u s$ ) is common in many of the gullies (Lindenmayer and McCarthy, 2001).

Adjacent to the southern and eastern borders of the plantation is a large area of unfragmented native eucalypt forest that is contiguous with Namadgi National Park and Kosciuszko National Park and in which the unfragmented control sites were situated. Trapping was conducted at 48 sites between approximately 1000 and $1200 \mathrm{~m}$ in altitude and in which all the forest types encountered in the remnant sites were represented (except that $R$. fructicosus was absent in the unfragmented sites and $E$. delegatensis was present in approximately $20 \%$ of sites).

For each site in the fragmented and unfragmented habitat, we measured a series of variables relating to the vegetation type and geographic context of the site (Table 1). The quantitative vegetation measures were averaged over three randomly placed $20 \times 10 \mathrm{~m}$ quadrats at each site. Measures of patch size and geographic isolation were only taken for remnant sites in the fragmented habitat.

\subsection{Fieldwork}

\subsubsection{Trapping at sites in the fragmented habitat}

All 23 remnant eucalypt patches within the study area were surveyed for the presence of $A$. agilis in March and April 2002. Each patch was trapped over a three-night period using 25 aluminium box traps (Elliott Scientific, Upwey, Victoria, Australia) baited with a mixture of peanut butter, honey, rolled oats and tinned cat food. Traps were spaced at $25 \mathrm{~m}$ intervals in a $5 \times 5$ trap grid or, in the case of narrow gully sites, a single linear arrangement. To estimate population sizes, we returned to all occupied remnant sites between May and July 2002 and set up grids with traps spaced at approximately $20 \mathrm{~m}$ intervals. Trapping was carried out at this density over the entire area of most sites (those up to approximately 15 ha in area) except the two largest sites, which were gullies approximately $3 \mathrm{~km}$ long and 30 to $200 \mathrm{~m}$ wide. At these sites the traps were placed in a single line at $20 \mathrm{~m}$ intervals except where the site width exceeded approximately $100 \mathrm{~m}$, where a second parallel

Table 1

Geographic and vegetation variables measured for each remnant eucalypt patch in the pine plantation

\begin{tabular}{|c|c|}
\hline Variable & Description \\
\hline \multicolumn{2}{|l|}{ Whole-site measures } \\
\hline Area & The area in hectares of the remnant eucalypt patch \\
\hline Dnat & The distance in metres to the nearest $>1000$ ha area of eucalypt forest \\
\hline Docc & The distance in metres to the nearest site occupied by $A$. agilis \\
\hline Gully & Did the site feature a gully? $(1=$ yes, $0=$ no $)$ \\
\hline \multirow[t]{2}{*}{ Slope/Ridge } & Was the site a dry slope or ridge? $(1=$ yes, $0=$ no $)$ \\
\hline & 0 for both 'Gully' and 'Slope/Ridge' indicate that the site was swampy \\
\hline Rad & Was Eucalyptus radiata among the dominant overstorey tree species at the site? $(1=\text { yes, } 0=\text { no })^{\mathrm{a}}$ \\
\hline VimDal & Was $E$. viminalis and/or $E$. dalrympleana among the dominant overstorey tree species at the site? $(1=\text { yes, } 0=\text { no })^{\mathrm{ab}}$ \\
\hline \multicolumn{2}{|c|}{ Measures averaged over the three $20 \times 10 \mathrm{~m}$ quadrats } \\
\hline Basal area $(C B A)$ & The sum of tree trunk areas $\left(\mathrm{cm}^{2}\right)$ measured at breast height \\
\hline Stags & The number of dead trees \\
\hline Shrub cover $(S C)$ & Percent ground cover by shrubs up to $1.5 \mathrm{~m}$ tall \\
\hline Litter & Average litter depth over each quadrat ranked from 0 (none) to high (5) \\
\hline $\log s$ & $\begin{array}{l}\text { The number of logs counted in the three quadrats weighted by the size of the logs. The diameter of each log was } \\
\text { measured and the count was weighted accordingly }(0-10 \mathrm{~cm} \text { : weight }=5,10-20 \mathrm{~cm} \text { : weight }=15,20-30 \mathrm{~cm} \text { : } \\
\text { weight }=25,>30 \mathrm{~cm} \text { : weight }=\text { diameter in } \mathrm{cm}) \text {. }\end{array}$ \\
\hline
\end{tabular}


trap line was used. Most sites were trapped for four consecutive nights, but those trapped in winter (June and July) were trapped over three nights to reduce the risk of trap-death (the reduced sampling effort only affects the precision, not magnitude, of the abundance estimates). Captured $A$. agilis were weighed, sexed and ear-clipped with a unique combination of $<2 \mathrm{~mm}$ diameter notches for individual identification and DNA sampling. Tissue samples were stored in $99.5 \%$ ethanol.

\subsubsection{Trapping at sites in the unfragmented habitat}

In June and July 2001, we trapped at 12 sites in unfragmented native forest, using 100 traps per site (four trap lines separated by approximately 30 metres with 25 traps per line spaced at approximately 15 metre intervals so the area encompassed by each grid was approximately $3.5 \mathrm{ha}$ ). To compare patterns of occupancy to the fragmented habitat, we only used detection records from the first line of 25 traps at each site so that the detection probability was not greater in the unfragmented habitat. However, we set up 100 traps and trapped at each site until at least 30 individuals had been sampled to provide adequate reference data on genetic diversity to compare to the fragmented sites. We also had detection data from 36 extra sites, using 10 traps per site over four nights. These smaller sites were used to provide samples for a separate genetic study of dispersal patterns but the trapping records provided additional data on the distribution of the species in unfragmented habitat. Although the site occupancy rate comparisons between fragmented and unfragmented habitats were made based on data collected in different (subsequent) years, we had also sampled eight of the large unfragmented sites in 2002 and 2003 so were able to determine if there was year-to-year variation in occupancy in the unfragmented habitat and therefore whether the data were appropriate to compare between the habitat contexts.

\subsection{Demographic analysis}

\subsubsection{Site occupancy and environmental determinants}

We estimated the site occupancy rate in the fragmented and unfragmented habitats as the proportion of sites in which the study species was detected. We used detection data from multiple surveys at each site to estimate detection probability and 'corrected' estimates of the site occupancy rate using the program PRESENCE (MacKenzie et al., 2002). This analysis was not conducted in the unfragmented habitat as the study species was detected at all sites. Sites in fragmented habitat were trapped for 3-9 nights in 2002 (including trapping to capture individuals for radio-telemetry not presented here) and each night was used as a separate survey for this analysis. Although, it is unlikely that there is no dependence in capture probability between nights, the mark-recapture model selection analysis (Section 2.4.2) did not identify a behavioural response to trapping, suggesting that there is not a very strong dependence in capture probabilities between nights. We used three pre-defined models that allow different numbers (1-3) of groups of sites with constant detection probabilities within each group. Akaike's Information Criterion (AIC) was used to rank the three models and the best model was used to provide estimates of detection probability and proportion of sites occupied. If the estimated detection probability was found to be sufficiently high (i.e. observed and corrected proportions were similar), we considered our site occupancy data sufficiently accurate to use for the model selection analysis.

Hierarchical partitioning analysis (Chevan and Sutherland, 1991) was used to estimate the independent contribution of the vegetation and geographic variables measured at each site to the variation in site occupancy in the fragmented habitat. We used a logistic regression model in the hier.part package (Walsh and MacNally, 2003) implemented in the software package $\mathrm{R}$ (version 1.7: http://www.r-project.org) to measure the independent and joint contribution of each standardised variable. The three variables with the largest independent contribution were fitted to a logistic model using $\mathrm{R}$ 1.7. The percentage of deviance explained by this model was compared to that explained by the best model selected using the genetic algorithm model selection procedure described in Fleishman et al. (2004) and fitted to a logistic regression model in $\mathrm{R} 1.7$.

The proximity of a site to the nearest occupied patch was an important contributor to the probability that a patch in the fragmented habitat would be occupied. However, this could be due to spatial autocorrelation of habitat quality variables that have a more important influence on occupancy, resulting in a pattern of spatial clustering of occupied sites. To determine whether the spatial clustering of occupied sites was associated with spatial clustering of habitat quality variables, we carried out multivariate spatial correlations (Wartenberg, 1985) of site occupancy with the six habitat quality variables that had the strongest independent effect on occupancy according to hierarchical partitioning. The analysis was done using four distance classes of $500 \mathrm{~m}$ each, since sites within approximately $500 \mathrm{~m}$ of another occupied site were more likely to be occupied. The significance of the multivariate correlation coefficient was estimated at each distance class by permuting the geographic locations of the sites and recalculating the coefficients 5000 times using PopTools 2.6 (Hood, 2004). If significant correlation of the two variables (outside the permuted $95 \%$ CI) was detected in the first distance class, this would suggest that the spatial clustering of occupancy among sites was significantly associated with the spatial clustering of the habitat quality variable. 


\subsubsection{Abundance estimation and environmental determi- nants}

The capture histories of individual $A$. agilis were used to estimate population size in the remnant patches using closed population mark-recapture methods. Trapping was carried out after the period of natal dispersal by males but before the breeding season. During radiotracking studies of over 50 individuals sampled from eight of the sites in fragmented habitat for up to 2 weeks in June and July we never observed antechinus moving between habitat patches (S. Banks, unpublished data). We therefore assumed closure of patch populations over the three or four-day trapping periods. We used the model selection option in the program CAPTURE (Otis et al., 1978; available from http://www.mbr-pwrc.usgs.gov/software) to determine the appropriate markrecapture abundance estimation model for the observed data. Density was measured for each patch site as the estimated population size divided by the site area in hectares. We did not attempt to compare abundance or density of $A$. agilis between the fragmented and unfragmented sites because the sites in unfragmented habitat were open populations and the spatial scale of the trapping grids was small in relation to the known home range size of the species (Lazenby-Cohen and Cockburn, 1991).

We used a Poisson regression model from the hier.part package (Walsh and MacNally, 2003) implemented in $\mathrm{R} 1.7$ to identify the site variables that were most influential on most-likely estimated population sizes among the occupied patches. The model contained the four variables with the largest independent effect on estimated abundance from the hierarchical partitioning analysis (four were used instead of three as the best abundance model identified by the genetic algorithm had four variables) using the "glm" function in R 1.7. The percentage deviance explained by this model was compared to that explained by the best Poisson model identified using the genetic algorithm model selection procedure (Fleishman et al., 2004).

\subsubsection{Sex ratio}

We compared the sex ratio of adults among sites in the fragmented and unfragmented habitats. Sex ratios were calculated from the ratio of trapped males and females over all sites in each habitat context. Although sample sex ratios may be biased due to higher capture probabilities among males than females (Hall, 1980), any sex differences in capture rate should be consistent between the habitat contexts. Any observed differences in sex ratio, therefore, reflect the relative proportions of males and females in the fragmented system relative to the unfragmented system. The $\chi^{2}$ statistic was used to test the null hypothesis that the sex ratio within each habitat context did not differ from 1:1 and a $2 \times 2 \chi^{2}$ contingency table was used to test the null hypothesis of homogeneous sex-ratios among the two habitat contexts. To account for inter-site variation, we also compared the mean sex ratio across sites between the habitat contexts using a single factor analysis of variance (ANOVA) implemented in Systat (version 10, SPSS Inc.).

\subsection{Genetic analyses}

\subsubsection{Genetic markers used}

We extracted DNA from ear tissue using the salting out method described in Sunnucks and Hales (1996) and resuspended the DNA pellet in $500 \mu \mathrm{L}$ TE buffer (10 mM Tris and $1 \mathrm{mM}$ EDTA). We used 15 microsatellite loci, including the 5 described in Kraaijeveld-Smit et al. (2002b) and 10 previously undescribed markers developed for A. agilis as described in Paetkau (1999) (Table 2). Single-stranded conformation polymorphism (SSCP) analysis combined with sequencing was used to analyse 492 base pairs (bp) of the mitochondrial control region (D-loop). The number of sampled individuals analysed was 499, including 329 from the fragmented habitat and 170 from the unfragmented habitat.

\subsubsection{Microsatellite PCR}

Microsatellite PCRs contained $\mathrm{MgCl}_{2}$ at the locusspecific concentration given in Table $2,75 \mathrm{mM}$ Tris$\mathrm{HCl}, 20 \mathrm{mM}\left(\mathrm{NH}_{4}\right)_{2} \mathrm{SO}_{4}, 0.01 \%$ Tween $20,0.02 \%$ bovine serum albumin, $200 \mu \mathrm{M}$ of dCTP, dGTP and dTTP, 20 $\mu \mathrm{M}$ dATP, 5 pmol of each primer, $0.03 \mu \mathrm{L}{ }^{33} \mathrm{P}$-labelled dATP at $10 \mathrm{mCi} / \mathrm{mL}, 0.25 \mathrm{U}$ Taq polymerase (MBI Fermentas) and $1 \mu \mathrm{L}$ template DNA, and were made up to $10 \mu \mathrm{L}$ with sterile distilled water. A MJ Research PTC100 thermal cycler was used, with an initial step of $94^{\circ} \mathrm{C}$ for $2 \mathrm{~min}$, followed by 30 cycles of $94{ }^{\circ} \mathrm{C}$ for $20 \mathrm{~s}, 30 \mathrm{~s}$ at the annealing temperature (Table 2) and $45 \mathrm{~s}$ at $72{ }^{\circ} \mathrm{C}$ with a final extension step of $72{ }^{\circ} \mathrm{C}$ for $3 \mathrm{~min}$. Products were run on $6 \%$ polyacrylamide sequencing gels and visualised using autoradiography.

\subsubsection{MtDNA PCR, SSCP and sequencing}

The primers MT15996L (Campbell et al., 1995) and MT15886H (Crowther et al., 2003) were used to amplify a fragment of the mitochondrial control region (D-loop) of approximately $600 \mathrm{bp}$ from 95 randomly selected samples. PCRs contained $10 \mathrm{mM}$ Tris- $\mathrm{HCl}, 50 \mathrm{mM}$ $\mathrm{KCl}, 0.08 \%$ Nonidet P40, $3.5 \mathrm{mM} \mathrm{MgCl}_{2}, 100 \mu \mathrm{M}$ of each dNTP, $0.02 \%$ bovine serum albumin, $5 \mathrm{pmol}$ of each primer, $0.05 \mu \mathrm{L}{ }^{33} \mathrm{P}$-labelled $\mathrm{dATP}$ at $10 \mathrm{mCi} /$ $\mathrm{mL}, 0.25 \mathrm{U}$ Taq polymerase (MBI Fermentas) and 1 $\mu \mathrm{L}$ of template DNA, and were made up to $10 \mu \mathrm{L}$ with sterile distilled water. Cycling conditions were as described in Crowther et al. (2003). After cycling, $10 \mu \mathrm{L}$ of formamide loading dye was added to each reaction and $3 \mu \mathrm{L}$ was loaded on a SSCP gel following Sunnucks et al. (2000). SSCP gels were run for $6 \mathrm{~h}$ at $250 \mathrm{~V}$ and $100 \mathrm{~mA}$ and were maintained at $4{ }^{\circ} \mathrm{C}$ with a 
Table 2

Primer sequences, annealing temperatures and magnesium chloride concentrations used in A. agilis microsatellite PCRs

\begin{tabular}{|c|c|c|c|c|c|c|c|}
\hline$\overline{\text { Locus }}$ & Primer & Sequence & Annealing temperature & {$\left[\mathrm{MgCl}_{2}\right](\mathrm{mM})$} & Multiplex PCR \# & \# alleles & $\mathrm{H}_{\mathrm{T}}$ \\
\hline Aa1A & Forward & TCAGCCTCGATATTTTTCTAATG & 54 & 2 & & 9 & 0.828 \\
\hline $\mathrm{Aa} 2 \mathrm{~B}$ & $\begin{array}{l}\text { Reverse } \\
\text { Forward }\end{array}$ & $\begin{array}{l}\text { AGCTCCTTTTGTATCCTAAC } \\
\text { GTACCACAAGATGCACCTAC }\end{array}$ & 54 & 1.5 & 6 & 13 & 0.854 \\
\hline $\mathrm{Aa} 2 \mathrm{E}$ & $\begin{array}{l}\text { Reverse } \\
\text { Forward } \\
\text { Reverse }\end{array}$ & $\begin{array}{l}\text { TTCACAGCCTAATGTCCCTA } \\
\text { TCTCGGCTCCTGTCAGTT } \\
\text { TCACATAGGGCAGCTTTCCTCCTG }\end{array}$ & 54 & 2 & 6 & 14 & 0.893 \\
\hline $\mathrm{Aa} 2 \mathrm{G}$ & $\begin{array}{l}\text { Forward } \\
\text { Reverse }\end{array}$ & $\begin{array}{l}\text { TTACACACATGCCCATTCAC } \\
\text { AGTTCTAAAACAGAGGTTCTT }\end{array}$ & 50 & 2 & 1 & 12 & 0.877 \\
\hline $\mathrm{Aa} 2 \mathrm{H} *$ & $\begin{array}{l}\text { Forward } \\
\text { Reverse }\end{array}$ & $\begin{array}{l}\text { GGAGAGTTTATGATTGTTGTC } \\
\text { GTTATCAGGTCAAAAAGCTCAC }\end{array}$ & 54 & 2.5 & 2 & 13 & 0.828 \\
\hline $\mathrm{Aa} 4 \mathrm{~A}$ & $\begin{array}{l}\text { Forward } \\
\text { Reverse }\end{array}$ & $\begin{array}{l}\text { TTTGATCCTCAGAGACTTGAT } \\
\text { CCAAATCTACGTAAAATATCC }\end{array}$ & 50 & 2.25 & 3 & 19 & 0.916 \\
\hline $\mathrm{Aa} 4 \mathrm{D}$ & $\begin{array}{l}\text { Forward } \\
\text { Reverse }\end{array}$ & $\begin{array}{l}\text { TCCACTCCCAATACTGACT } \\
\text { TGATTAGGTGCCCACACTA }\end{array}$ & 54 & 2 & & 5 & 0.557 \\
\hline $\mathrm{Aa} 4 \mathrm{~J} *$ & $\begin{array}{l}\text { Forward } \\
\text { Reverse }\end{array}$ & $\begin{array}{l}\text { TCTTCAGTCTCTCAATGAGTT } \\
\text { AGAACACTCTAACAACATCCT }\end{array}$ & 54 & 2.5 & 5 & 18 & 0.894 \\
\hline $\mathrm{Aa} 4 \mathrm{~K} *$ & $\begin{array}{l}\text { Forward } \\
\text { Reverse }\end{array}$ & $\begin{array}{l}\text { TCTGTGGAGCCTCTAGAGAAT } \\
\text { AAGAGGATAACCCATTCAGA }\end{array}$ & 50 & 2 & 1 & 11 & 0.826 \\
\hline Aa7D* & $\begin{array}{l}\text { Forward } \\
\text { Reverse }\end{array}$ & $\begin{array}{l}\text { GGATTTGATCTCAGGTTTTC } \\
\text { ATATCCACCAATGACTGCAA }\end{array}$ & 54 & 2.5 & 2 & 12 & 0.809 \\
\hline $\mathrm{Aa} 7 \mathrm{~F}$ & $\begin{array}{l}\text { Forward } \\
\text { Reverse }\end{array}$ & $\begin{array}{l}\text { ATTGCCTGTTGCTACCAT } \\
\text { ACACATAACTCCTAAGAATTCCT }\end{array}$ & 50 & 2.5 & 4 & 14 & 0.880 \\
\hline $\mathrm{Aa} 7 \mathrm{H}$ & $\begin{array}{l}\text { Forward } \\
\text { Reverse }\end{array}$ & $\begin{array}{l}\text { AATTCAGTTGAGTCCACTTTG } \\
\text { GTGCTTTCTCTGTCTTTCC }\end{array}$ & 50 & 2.25 & 3 & 29 & 0.932 \\
\hline Aa7K & $\begin{array}{l}\text { Forward } \\
\text { Reverse }\end{array}$ & $\begin{array}{l}\text { TTTCTGGATGAACAGTTTGA } \\
\text { GAGATGTGAGCAGTTAGTGGAC }\end{array}$ & 50 & 2.5 & 4 & 14 & 0.902 \\
\hline Aa7M & $\begin{array}{l}\text { Forward } \\
\text { Reverse }\end{array}$ & $\begin{array}{l}\text { TGCTTTGTTCTTGCTAAGTA } \\
\text { ACAATCATATGTTTATGTAGCC }\end{array}$ & 50 & 2 & 1 & 12 & 0.791 \\
\hline Аa7O* & $\begin{array}{l}\text { Forward } \\
\text { Reverse }\end{array}$ & $\begin{array}{l}\text { GTCTTTGGATAATTGAAGTCTG } \\
\text { GAATGAGGATCTAAGTGAATGT }\end{array}$ & 54 & 2.5 & 5 & 16 & 0.893 \\
\hline
\end{tabular}

Where multiple loci were amplified together in the same PCR, that PCR is given a number in the multiplex PCR \# column. The number of alleles and expected heterozygosity estimated from allele frequencies observed in the unfragmented sites $\left(\mathrm{H}_{\mathrm{T}}\right)$ are also provided. The microsatellites marked with an asterisk were originally described in (Kraaijeveld-Smit et al., 2002b).

refrigeration pump. Products were visualised using autoradiography.

Because SSCP is purported to be less efficient at identifying sequence differences among larger PCR products (Sunnucks et al., 2000), we used the following procedure to identify a restriction digest that would cut the $600 \mathrm{bp}$ PCR products approximately in half prior to SSCP. PCRs were performed on ten samples representing two examples of each of five haplotypes suggested to be different on the basis of SSCP of uncut PCR products. PCRs were carried out in $20 \mu \mathrm{L}$ reactions using the same concentrations of reagents as described above but excluding the ${ }^{33} \mathrm{P}$-labelled dATP. After PCR cycling, 4 $\mu \mathrm{L}$ glycerol loading dye was added to each reaction and $20 \mu \mathrm{L}$ of each was electrophoresed on a $2 \%$ agarose gel. The 600-bp band was then purified from the gel using a Bresa-Clean DNA Purification Kit (BresaTec). Approximately $50 \mathrm{ng}$ of the purified PCR product was sequenced using labelled dideoxynucleotides on an ABI 377 DNA Sequencer. Sequences were aligned using ClustalW (Thompson et al., 1994) and restriction sites were identified using Webcutter 2.0 (available from http://www.firstmarket.com/cutter/cut2.html). A Mph1103I restriction site that would cut the PCR product into fragments of approximately 250 and $350 \mathrm{bp}$ was identified in all 10 sequences. Prior to subsequent SSCP gels, the $10 \mu \mathrm{L}$ PCR product was digested at $37^{\circ} \mathrm{C}$ overnight with 1 unit $M p h 1103 \mathrm{I}, 10 \mathrm{mM}$ Tris- $\mathrm{HCl}, 10 \mathrm{mM}$ $\mathrm{MgCl}_{2}, 100 \mathrm{mM} \mathrm{KCl}, 0.1 \mathrm{mg} \mathrm{mL}$ bovine serum albumin in a reaction made up to $40 \mu \mathrm{L}$ with sterile distilled water. SSCP gels were performed as described earlier and 34 different patterns were recognised. We sequenced 85 samples (including multiple representative samples of each pattern) as described above and obtained $492 \mathrm{bp}$ of sequence for all samples. We compared sequences among samples with the same banding pattern and with different banding patterns to determine whether the SSCP method accurately resolved sequence differences.

\subsubsection{Analysis of genetic signs of isolation}

We compared the genetic diversity in fragment populations with that at the 12 large unfragmented control sites and used a simulation approach to estimate the 
proportion of genetic variation that would have been lost from the fragment populations if they had been isolated. First, we tested for departures from Hardy-Weinberg expectations for the microsatellite loci in the unfragmented populations using Genepop version 3.4 (Raymond and Rousset, 1995). Genetic diversity was measured in each site as observed and expected heterozygosity $\left(\mathrm{H}_{\mathrm{O}}\right.$ and $\mathrm{H}_{\mathrm{S}}$ : estimated using FSTAT version 2.9.3.2 (Goudet, 1995)) and allelic richness (AR: the average number of alleles per locus standardised for unequal sample sizes between sites). Allelic richness was estimated using the method of El Mousadik and Petit (1996) implemented in the program CONTRIB (Petit et al., 1998). We tested for significant differences in these parameters between habitat contexts using MannWhitney U tests in Systat version 10 (SPSS Inc.). The observed difference between habitat contexts was compared, which was estimated by simulation using the software.

We used the software Easypop version 1.8 (Balloux, 2001) to conduct simulations to estimate the change in genetic diversity expected if the populations in the fragmented habitat had been isolated. The simulations for the microsatellite data used the estimated numbers of males and females in each fragmented site in 2002 and those for the mitochondrial data used only the numbers of females. Simulated populations started with genotypes composed of randomly sampled alleles from a possible 20 allelic states per locus and we ran the simulations for 25 generations under a migration scenario such that no population was isolated so that the genetic diversity of the simulated populations prior to isolation more closely resembled that of real unfragmented populations (see Appendix A for full simulation parameters). The migration rate was then set to zero for the number of generations estimated to have passed since the initial fragmentation event occurred. The number of generations to have passed since fragmentation was estimated as the number of years since the eucalypt forest surrounding each site was cleared (between 47 and 56) divided by the average length of an A. agilis generation [1.19 years for the microsatellite simulations - calculated from the proportion of males and females observed over 3 years to survive to a second breeding season $(0 \%$ and $32 \%$, respectively) and the adult sex ratio in fragmented habitat ( 1 male to 1.45 females, see Section 3); 1.32 years for mitochondrial DNA simulations - where only females are considered]. The percentage difference between generation 25 and the end of the simulation in within-site expected heterozygosity $\left(\mathrm{H}_{\mathrm{S}}\right)$ and corrected allelic richness (AR-1, since a locus with one allele has no variation) represents the simulated degree of genetic variation lost due to population isolation. These values were averaged over simulations and populations and the simulated change was compared to the observed difference in these parameters between the unfragmented and fragmented sites. We also simulated this process using three different but realistic mutation rates for the markers used to determine the degree to which mutation rate assumptions could affect the results.

\section{Results}

\subsection{Demographic analyses}

\subsubsection{Site occupancy}

Agile antechinus were detected at all sites in the unfragmented habitat and at 16 of 23 remnant eucalypt sites $(69.6 \%)$ in the pine plantation (Fig. 2). Although the occupancy data in the fragmented and unfragmented habitats were collected in different years, a subset of the unfragmented sites $(n=8)$ that were also trapped in 2002 and 2003 (data not shown) revealed no variation in site occupancy in the unfragmented habitat between years, suggesting that the comparison between habitat contexts in subsequent years was not inappropriate in this instance. The most appropriate model selected by AIC to explain the variation in detection probability between sites in the fragmented habitat was two groups with probabilities of group membership of 0.885 and 0.115 and per-survey detection probabilities of 0.992 and 0.775 , respectively. The estimated proportion of occupied sites was $69.7 \%$. This suggests that the observed pattern of site occupancy very accurately represented the true pattern and that it was appropriate to use the raw occupancy data in the analyses to determine the effects of site variables on occupancy.

Hierarchical partitioning revealed that the most important independent contributions to the variation between sites in occupancy were made by the variables basal area ( $C B A: 23.4 \%)$, distance to the nearest occupied site (Docc: $24.6 \%$ ) and the presence of $E$. viminalis or E. dalrympleana as one of the dominant eucalypt species at the site (VimDal: 9.8\%) (Fig. 3). When the sites were ranked according to their basal area value, the 14 sites with the highest basal area were all occupied. All sites that were within $150 \mathrm{~m}$ of another occupied site $(n=10)$ were occupied, $83 \%$ of sites that were within $500 \mathrm{~m}$ of an occupied site were occupied $(n=18)$ and only $20 \%$ of sites that were over $500 \mathrm{~m}$ from the nearest occupied site were occupied $(n=5)$. The one site that was occupied and further than $500 \mathrm{~m}$ from the nearest occupied site was a large patch (19 ha) with a very high basal area value. These independent variables were fitted to a logistic model that explained $70 \%$ of the deviance (Table 3: Occupancy model 1). The significance level for the test that the VimDal term had a non-zero coefficient was only 0.33 and it was found that the model performed better when fitted without this term (Table 3: Occupancy model 3). The best logistic model to 


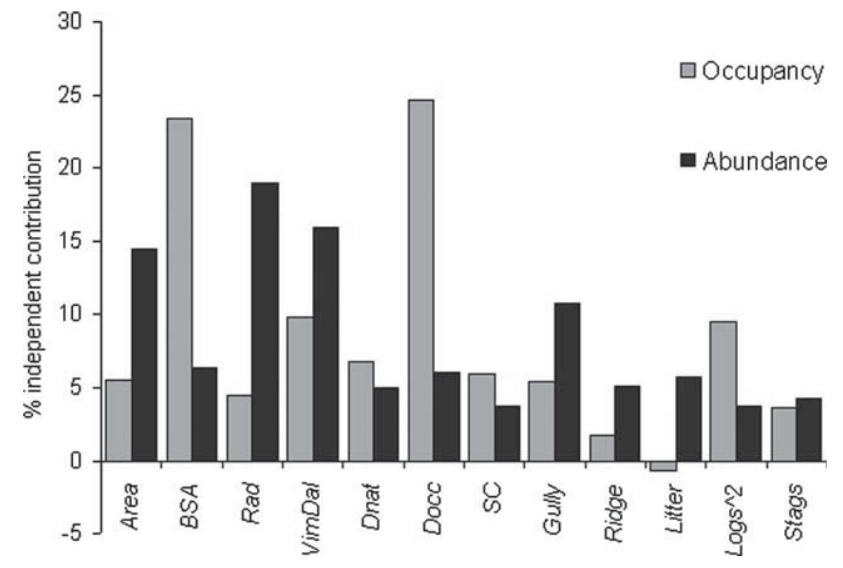

Fig. 3. Percentage-distribution of independent effects by site variables estimated by hierarchical partitioning on site occupancy by Antechinus agilis and estimated population size (abundance).

Table 3

Coefficients for logistic regression models to explain the observed patterns of site occupancy in the remnant habitat patches in the pine plantation (mean, standard deviation and $p$-value for the null hypothesis that the coefficient is not significantly different from zero)

\begin{tabular}{lrll}
\hline Model & Mean & SD & $p$ \\
\hline Occupancy model & $\left(R^{2}=0.696\right)$ & & \\
Basal area $(C B A)$ & 11.484 & 4.882 & 0 \\
Docc & -5.075 & 2.784 & 0.004 \\
VimDal & 0.898 & 2.278 & 0.331 \\
Intercept & 6.697 & 3.403 & 0.012 \\
Occupancy model $2\left(R^{2}=0.854\right)$ & & \\
Basal area $(C B A)$ & 13.654 & 5.696 & 0 \\
Docc & -8.016 & 4.151 & 0 \\
Slopel Ridge & -6.677 & 4.196 & 0.034 \\
Intercept & 8.515 & 6.599 & 0.062 \\
Occupancy model $3\left(R^{2}=0.739\right)$ & & \\
Basal area $(C B A)$ & 12.502 & 5.482 & 10 \\
Docc & -6.591 & 4.32 & 0.005 \\
Intercept & 4.984 & 4.832 & 0 \\
\hline Occupacy & &
\end{tabular}

Occupancy model 1 contained the three independent variables with the greatest independent effect on occupancy, as determined by hierarchical partitioning. Occupancy model 2 is the best model identified by the genetic algorithm model selection approach and occupancy model 3 is the same model fitted without the Slope/Ridge variable.

explain site occupancy identified by the genetic algorithm model selection procedure is presented as "Occupancy model 2" in Table 3 and, here too, the variables with the largest coefficients were basal area and distance to the nearest occupied site. This model also predicted that the probability of a site being occupied was lower if the site contained a slope or ridge. This variable had only a weak independent contribution (1.7\%), and in fact more sites that fitted this category were occupied than unoccupied. However, the same model fitted without this variable (Table 3: Occupancy model 3) explained considerably less of the deviance than the original model ( $74 \%$ compared to $85 \%$ ).
Table 4

Summary of analyses of spatial cross-correlation of site occupancy with the six habitat quality variables with the largest independent contribution to site occupancy as predicted by hierarchical partitioning

\begin{tabular}{lllll}
\hline Variable (+ occupancy) & \multicolumn{5}{l}{ Distance class $(\mathrm{m})$} \\
\cline { 2 - 5 } & $1-500$ & $501-1000$ & $1001-1500$ & $1501-2000$ \\
\hline Basal area $(C B A)$ & 0.426 & 0.423 & 0.563 & 0.131 \\
Gully & 0.677 & 0.833 & 0.692 & 0.287 \\
Logs & 0.571 & 0.92 & 0.074 & 0.652 \\
VimDal & 0.176 & 0.961 & 0.346 & 0.084 \\
Rad & 0.304 & 0.778 & 0.278 & 0.086 \\
Shrub cover (SC) & 0.915 & 0.743 & 0.906 & 0.378 \\
\hline
\end{tabular}

The table shows the proportion of randomised cross-correlation coefficients that were greater than or equal to the observed coefficient in each distance class. Values of less than 0.025 and greater then 0.975 would mean that there was significant positive or negative crosscorrelation (respectively) between that variable and site occupancy for that distance class.

No significant spatial cross-correlations were detected between patch occupancy and the six habitat quality variables that had the strongest independent effect on occupancy according to hierarchical partitioning (Table 4). This suggests that the apparent influence on patch occupancy of the degree of isolation from other occupied sites is not due to spatial autocorrelation of other habitat quality variables.

\subsubsection{Abundance estimation}

Population sizes in the occupied patches were estimated using the $\mathrm{M}_{\mathrm{h} \text {-jackkknife }}$ model, which assumes variation in capture probability between individuals (Burnham and Overton, 1978), in the program CAPTURE. Estimated population sizes ranged from 3 ( $95 \%$ confidence interval 3 to 3 ) to 85 (95\% CI $77-102)$ and the summed population size estimate across the 16 sites studied was 377 (95\% CI 325-517). The distribution of most-likely estimated population sizes among the 16 patch sites is presented in Fig. 4. The mean, median and standard deviation of the density of $A$. agilis at each

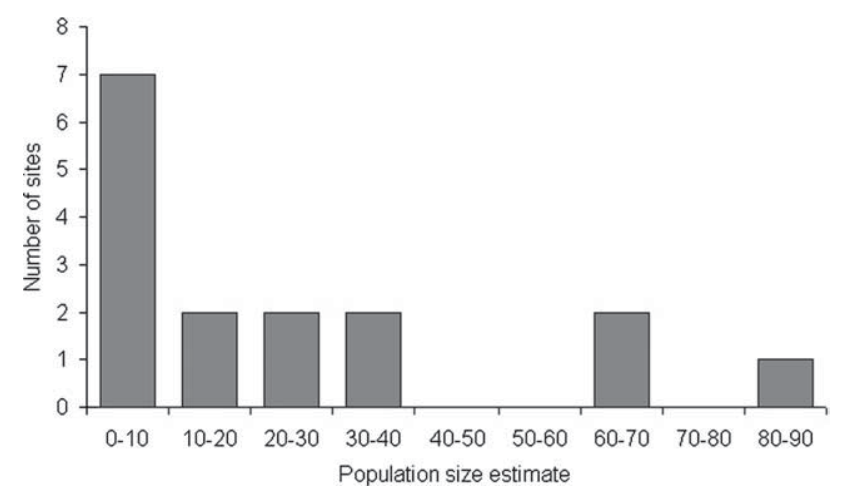

Fig. 4. Frequency distribution of most likely estimated population sizes among the 16 patch populations, as estimated using the $\mathrm{M}_{\mathrm{h} \text {-jackknife }}$ closed population model in the program CAPTURE. 
fragmented site were $4.74 \mathrm{ha}^{-1}$ (95\% CI 4.01-6.63), 2.5 $\mathrm{ha}^{-1}\left(95 \%\right.$ CI 1.93-3.41) and $6.01 \mathrm{ha}^{-1}$ (for the mostlikely estimate), respectively. The range of estimated densities across all patch sites was $0.24 \mathrm{ha}^{-1}(95 \% \mathrm{CI}$ $0.24-0.24)$ to $22.67 \mathrm{ha}^{-1}$ (95\% CI 19.33-30.67). There was no significant correlation between patch area and the most-likely density estimate in the fragmented habitat (Pearson correlation coefficient $=0.059, P=0.827$ ).

Hierarchical partitioning using a Poisson regression model identified the presence of E. radiata (Rad: $18.9 \%$ ) and E. viminalis or E. dalrympleana (VimDal: $15.9 \%$ ) as dominant overstorey tree species, the geographic area of the patch (Area: 14.4\%) and whether or not the site featured a gully (Gully: $10.8 \%$ ) as the variables with the largest independent contribution to the variance in abundance among the occupied fragmented sites. A Poisson regression model containing these variables explained $73.9 \%$ of the deviance in estimated population size (Table 5, abundance model 1). The best Poisson model identified by the genetic algorithm model selection explained $85.1 \%$ of the variance in estimated abundance (Table 5: abundance model 2) and featured the variables Rad and VimDal, as well as two variables not identified as being among the most important independent contributors by hierarchical partitioning, the distance to an area (>1000 ha) of unfragmented native forest (Dnat) and the squared measure of the weighted number of logs counted in the quadrats $\left(\operatorname{Logs}^{2}\right)$. As with the first abundance model, the presence of $E$. radiata and E. viminalis or E. dalrympleana had a strong positive relationship with abundance in this model. Estimated population size was predicted to have a negative relationship with increasing distance from large areas of

Table 5

Coefficients for the Poisson regression models to explain the variation in most-likely estimated population size among the sites in the fragmented habitat that were occupied (means, standard errors and $p$-value for the null hypothesis that the coefficient is not significantly different from zero)

\begin{tabular}{|c|c|c|c|}
\hline Model & Mean & SE & $p$ \\
\hline \multicolumn{4}{|c|}{ Abundance model $1\left(R^{2}=0.739\right)$} \\
\hline Rad & 1.448 & 0.217 & $<0.0001$ \\
\hline VimDal & 1.061 & 0.199 & $<0.0001$ \\
\hline Gully & -0.503 & 0.147 & $<0.0001$ \\
\hline Area & 0.354 & 0.046 & $<0.0001$ \\
\hline Intercept & 1.165 & 0.242 & $<0.0001$ \\
\hline \multicolumn{4}{|c|}{ Abundance model $2\left(R^{2}=0.851\right)$} \\
\hline Rad & 1.958 & 0.246 & $<0.0001$ \\
\hline VimDal & 1.574 & 0.213 & $<0.0001$ \\
\hline Dnat & -0.474 & 0.049 & $<0.0001$ \\
\hline $\operatorname{Logs}^{2}$ & 0.466 & 0.063 & $<0.0001$ \\
\hline Intercept & 0.217 & 0.255 & 0.407 \\
\hline
\end{tabular}

Abundance model 1 contains the four variables that were identified by hierarchical partitioning as having the largest independent effect on abundance. Abundance model 2 is the best model identified by the genetic algorithm model selection procedure to explain the observed variation in abundance. eucalypt forest and a positive relationship with the abundance and/or size of logs at the site.

\subsubsection{Sex ratio}

The sample sex ratio across all sites in the unfragmented habitat was significantly male-biased (male: female ratio $\left.=1.64: 1, \quad \chi^{2}=14.75, \quad \mathrm{df}=1, \quad p=0.0001\right)$, whereas a significantly female-biased sex ratio was observed among individuals sampled from the fragmented habitat (male: female ratio $=1: 1.45, \chi^{2}=11.51, \mathrm{df}=1$, $p=0.0007)$. A $2 \times 2 \chi^{2}$ contingency table revealed that the sex ratios in the two habitat contexts were not equal $\left(\chi^{2}=26.26, \mathrm{df}=1, p<0.0001\right)$. The mean sex ratio across sites also differed significantly between habitat contexts (ANOVA: SS (habitat context) $=0.12, \mathrm{df}=1$, $F$-ratio $=4.69, p=0.043)$. Although smaller populations in the fragmented habitat generally exhibited a higher ratio of males to females and larger populations the opposite, the rank correlation between estimated population size and sex ratio was not significant (Spearman rank correlation coefficient $=-0.305, p=0.251)$.

\subsection{Genetic analysis}

Genotype proportions did not differ significantly from Hardy-Weinberg expectations at any of the unfragmented habitat sites for the 15 microsatellite loci used. The number of alleles and expected heterozygosity at the microsatellite loci for the unfragmented sites are presented in Table 2. Examination of the 85 sequenced mitochondrial SSCP patterns (including similar patterns on different gels) revealed the presence of 22 different haplotypes. Seventeen haplotypes were identified among the samples from the unfragmented sites and 13 from the fragmented sites. Although only eight haplotypes were found in both habitat contexts, their summed frequencies in the unfragmented and fragmented habitats were 0.795 and 0.883 , respectively, indicating that only rare haplotypes were restricted to one or the other. The average values of allelic richness and gene diversity in the fragmented and unfragmented populations are presented for both types of markers in Table 6 . The only significant difference in diversity parameters between the habitat contexts was a lower within-site expected microsatellite heterozygosity in the fragmented relative to the unfragmented sites.

The observed differences in genetic diversity (AR and $H_{E}$ ) between populations in the two habitat contexts were not consistent with isolation of patch populations due to establishment of the pine plantation (Table 7). Fig. 5 shows one replicate of the simulated change in gene diversity over time for the microsatellite and mitochondrial markers under a range of mutation schemes. For all simulations, over half of the final loss of gene diversity occurred within the first 10 generations. Although the level of gene diversity at the end of the 
Table 6

Mean genetic diversity parameters for microsatellite and mitochondrial control region data from the fragmented and unfragmented habitat contexts

\begin{tabular}{|c|c|c|c|c|c|}
\hline & \multicolumn{3}{|c|}{ Microsatellite diversity } & \multicolumn{2}{|c|}{ Mitochondrial diversity } \\
\hline & \multirow{2}{*}{$\frac{\text { Allelic richness }}{(5 \text { alleles })}$} & \multicolumn{2}{|c|}{ Heterozygosity } & \multirow{2}{*}{$\frac{\text { Allelic richness }}{(5 \text { alleles })}$} & \multirow{2}{*}{$\begin{array}{l}\text { Haplotypic diversity } \\
\mathrm{H}_{\mathrm{S}}\end{array}$} \\
\hline & & $\mathrm{H}_{\mathrm{S}}$ & $\mathrm{H}_{\mathrm{O}}$ & & \\
\hline Unfragmented & 2.828 & 0.860 & 0.865 & 1.647 & 0.634 \\
\hline Fragmented & 2.744 & 0.844 & 0.854 & 1.663 & 0.669 \\
\hline$p$ & 0.090 & 0.009 & 0.311 & 0.416 & 0.991 \\
\hline
\end{tabular}

Significance testing was done using Mann-Whitney $U$ tests. $\mathrm{H}_{\mathrm{S}}$ refers to average expected heterozygosity (or haplotypic diversity) based on allele frequencies at each site and $\mathrm{H}_{\mathrm{O}}$ is expected heterozygosity.

Table 7

Observed percentage difference in within-site expected heterozygosity $\left(\mathrm{H}_{\mathrm{S}}\right)$ and allelic richness (AR: corrected by subtracting 1 allele) between fragmented and unfragmented habitats compared to that expected based on simulations assuming complete isolation of the populations in fragmented habitat

\begin{tabular}{|c|c|c|c|c|}
\hline & \multicolumn{2}{|c|}{ Mitochondrial } & \multicolumn{2}{|c|}{ Microsatellite } \\
\hline & $\mathrm{H}_{\mathrm{S}}$ & AR & $\mathrm{H}_{\mathrm{S}}$ & AR \\
\hline Observed change & +5.928 & +2.413 & -1.896 & -4.110 \\
\hline Simulated - lower limit & -59.868 & -59.398 & -66.676 & -75.756 \\
\hline Simulated - upper limit & -77.148 & -77.971 & -69.751 & -77.407 \\
\hline
\end{tabular}

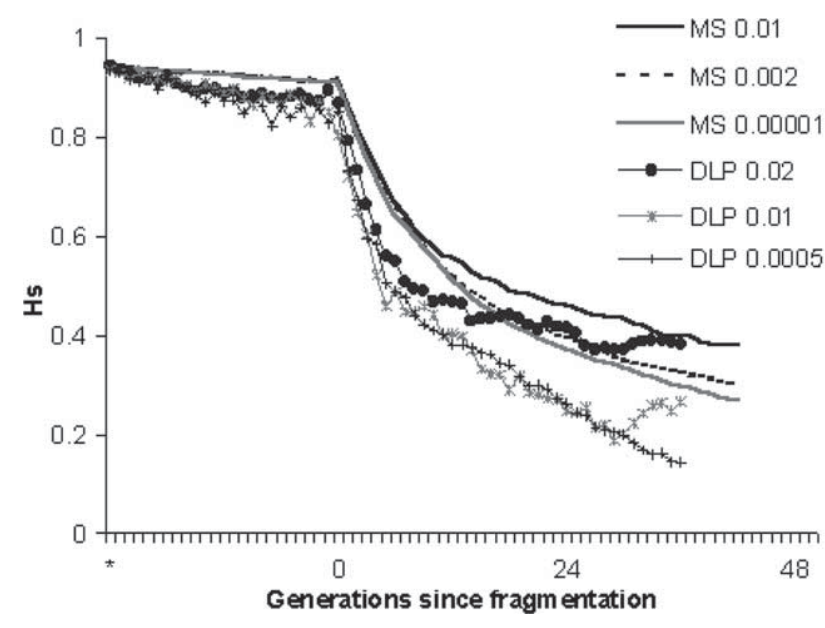

Fig. 5. Plots showing one simulation of the change in expected heterozygosity $\left(\mathrm{H}_{\mathrm{S}}\right)$ for microsatellite markers and mitochondrial control region DNA over 50 years assuming isolation of the 16 populations in the fragmented habitat. Simulations were carried out using several mutation schemes (See Appendix A). The legend shows the mutation schemes for the microsatellite (MS and mutation rate) and mitochondrial (DLP and mutation rate) markers. Prior to simulating the effects of isolation on these populations the simulations were run for 25 generations under a migration scenario in which no populations were isolated.

simulations was affected by the mutation rate, the reduction in genetic diversity in the simulations was always much greater than the observed difference between the fragmented and unfragmented sites.

The complete isolation of patch populations is an extreme scenario and if the populations were partially isolated we would expect populations that are smaller or more isolated to have lost a greater proportion of genetic diversity. Linear regression analysis was used to determine whether patch populations exhibited a relationship between genetic diversity $\left(\mathrm{H}_{\mathrm{E}}, \mathrm{H}_{\mathrm{O}}, \mathrm{AR}\right.$ and and the average number of alleles per locus) and site characteristics (estimated population size, sample size, distance to nearest occupied site, distance to nearest $>1000$ ha area of unfragmented habitat and number of years since the initial clearing of the surrounding habitat). No significant relationships were identified between any of the genetic and demographic or geographic variables.

\section{Discussion}

\subsection{Agile antechinus populations in eucalypt remnants in the pine plantation are not isolated}

Lindenmayer et al. (1999) hypothesised that the persistence of $A$. agilis populations in remnant patches at Tumut could be due to (1) large population sizes that are relatively resistant to extinction, (2) a high dispersal capability of the species through the pine matrix such that the extant populations are not isolated, or (3) the presence of $A$. agilis populations in the pine matrix itself, such that the patch populations are not really fragmented. We consider the latter explanation unlikely as the only (rare) detections of $A$. agilis in the pine plantation were made at windrows of eucalypt logs from the initial clearfelling event (Lindenmayer et al., 1999). In the section of the plantation studied here, these windrows have largely disappeared during forestry thinning and clearfelling operations. Given that over $40 \%$ of the fragment populations studied here were estimated to 
contain less than 10 individuals, we also consider the first explanation unlikely. Our genetic evidence revealed that these populations are not simply isolated remnants of the species' pre-fragmentation distribution in the area, supporting the hypothesis of a high degree of population connectivity in the fragmented system.

The realistic simulation scenarios showed that if the establishment of the pine plantation had caused the isolation of $A$. agilis populations in the remnant eucalypt patches, a large reduction in mitochondrial and microsatellite genetic diversity would have been observed. The degree to which this was expected to occur depended on the mutation rates specified. However, under all scenarios, the expected loss of genetic variation was much greater than the observed difference between the fragmented and unfragmented sites and occurred over a very short timescale. In previous studies where fragmentation is known to have caused the isolation of small populations (Hitchings and Beebee, 1998; Srikwan and Woodruff, 2000; Vucetich et al., 2001), loss of genetic diversity is more like that observed in our simulations. Tallmon et al. (2002) used a similar approach to show that the reduction of mitochondrial haplotypic diversity (gene-flow by females only) in California red-backed vole (Clethrionomys californicus) populations in forest fragments isolated by clear-cutting, relative to those in unfragmented controls, was consistent with predictions of simulations assuming demographic isolation of the fragmented populations. However, the simulated loss of nuclear (microsatellite) heterozygosity (gene flow by males and females) in the fragmented sites relative to the controls was not observed, suggesting that fragmentation had severely reduced dispersal by females but not males. Our results suggest that the pine plantation matrix does not pose a complete barrier to dispersal by either sex of $A$. agilis. This is important because dispersal by both sexes is required for recolonisation of habitat patches following local extinctions. The only significant difference in genetic diversity between the habitat contexts was a minor reduction in average expected heterozygosity in the fragment sites relative to the control sites. It is possible that allelic proportions are less even in the fragmented populations compared to those in unfragmented populations due to differences in kin structure, which would result in a lower expected heterozygosity.

The incorporation of demographic data into simulations to predict the effects of fragmentation on genetic diversity is important if the genetic data are to be used to make inferences about fragmentation impacts on population connectivity (Tallmon et al., 2002). The absence of a reduction in genetic diversity in fragmented populations may be due to insufficient time since fragmentation, a large effective population size in the fragmented populations, or ongoing gene flow among fragments and/or surrounding continuous forest. Keller and Largiader (2003) found that although road con- struction had caused significant population subdivision in a flightless ground beetle (Carabus violaceus), significant reductions in genetic variation were observed only in the two smallest fragments they sampled. Potential problems with our simulation approach include the assumption of stable population sizes throughout the simulations. This may be unrealistic but since effective population size $\left(N_{\mathrm{e}}\right)$ in fluctuating populations is equal to the lowest value reached, and $N_{\mathrm{e}}$ in any case is probably substantially lower than actual population size (Frankham, 1995a), an even greater loss of genetic variation would be expected under a fluctuating population model. Mutation rates may affect the level of genetic variation but none of the simulated mutation rates resulted in changes in genetic diversity as minor as those observed between the fragmented and unfragmented populations.

The genetic evidence suggesting a lack of isolation of A. agilis populations in habitat fragments in the pine plantation is similar to that for the bush rat (Rattus fuscipes) at Tumut (Lindenmayer and Peakall, 2000). Although these authors did not specifically test for differences in genetic variation at microsatellite loci between fragmented and unfragmented sites, their data reveal no major differences between the habitat contexts. In contrast, populations of the marsupial greater glider (Petauroides volans) in remnant patches at Tumut show evidence of a significant loss of microsatellite genetic variation relative to pre-fragmentation samples and contemporary samples from unfragmented sites, suggesting that populations of this species have been to some extent isolated in the habitat patches in the pine plantation (A. Taylor et al., unpublished data). Comparative studies of genetic differentiation (an indirect estimator of dispersal rate) among populations of different species in fragmented habitats have revealed that generalist species (i.e. those that are able to use the matrix to some degree) are less likely than habitat specialists to be isolated by habitat fragmentation (Mech and Hallett, 2001; Brouat et al., 2003). P. volans may be a highly restricted habitat specialist in this region as it feeds primarily on eucalypt leaves and may have more difficulty than A. agilis in traversing large areas of pine plantation.

\subsection{Factors influencing site occupancy and abundance in the fragmented system}

The occupancy rate of $70 \%$ in the fragmented sites compared to $100 \%$ in the unfragmented sites suggests that fragmentation itself affects site occupancy. The sites surveyed in the unfragmented habitat included all of the vegetation and topography-related habitat types represented in the sites sampled in the fragmented system, including those that would have been predicted to be poor quality habitat in the fragmented system. A possi- 
ble contributor to reduced occupancy rates in fragmented sites is that they were almost always dominated by one habitat type (i.e. reduced habitat diversity), whereas the unfragmented forest presented a diversity of habitat types adjacent to each other. Despite the apparent negative impact of fragmentation on site occupancy, the mean density of $A$. agilis in the fragmented sites $\left(4.74 \mathrm{ha}^{-1}\right)$ was higher than that previously reported for populations in unfragmented eucalypt forest (1-2 $\mathrm{ha}^{-1}$ ) by Dickman (1980) but lower than that reported for coastal heathland $\left(21 \mathrm{ha}^{-1}\right)$ by Wilson et al. (1986). The large variation in density between patch sites may be explained by the fact that each patch site generally featured only one habitat type but there was a large amount of variation between patches in habitat characteristics. A potential contributing factor to the very high densities detected in some patches is that agile antechinus may occasionally forage in the pine plantation near their "home" patch (S. Banks, unpublished data) so the populations that were sampled in these patches may be accessing food resources over a larger area.

Although genetic analyses suggest that none of the populations in the fragmented system are isolated, our finding that the geographic isolation of a patch had the greatest independent effect on patch occupancy suggests that the distribution of $A$. agilis in the fragmented system is limited by its dispersal capability. Hanski's (1994) incidence-function model describes patch occupancy as a function of patch area and isolation. Our results support the importance of patch isolation, but we found species-specific habitat quality variables to be more important than patch area in for both patch occupancy and abundance. In agreement with recent findings for A. stuartii (Cox et al., 2003), cumulative basal area was positively correlated with patch occupancy. Antechinus agilis usually nest in the hollows of standing trees, and since large trees are more likely to have hollows, basal area is likely to be a good surrogate for the number of available nests in the site (Cockburn and LazenbyCohen, 1992; Lindenmayer et al., 2000).

Patch area was an important predictor of abundance (inferred from capture rates) of $A$. agilis and $A$. stuartii in previous studies in this and other fragmented systems (Dunstan and Fox, 1996; Lindenmayer et al., 1999; Knight and Fox, 2000). However, in two of these studies its influence was moderated by edge effects (Dunstan and Fox, 1996) or habitat structure (Knight and Fox, 2000). In contrast, Cox et al. (2003) did not find that landscape variables, including patch area and isolation, influenced abundance of $A$. stuartii in fragments on the Eastern Dorrigo Plateau, New South Wales. The variation in estimated population size in the occupied patches in this study was influenced predominantly by the presence of the eucalypts $E$. radiata and $E$. viminalis and/or E. dalrympleana. Radiotracking at Tumut suggests that these species are often used as nest trees by $A$. agilis
(S. Banks unpublished data), and E. viminalis and $E$. dalrympleana also shed large amounts of bark that may provide habitat for the invertebrates that make up a large component of the diet of A. agilis (Hall, 1980). In concordance with the findings of Suckling and Heislers (1978), eucalypt patch sites that contained a gully generally had larger estimated population sizes than those that did not.

Two approaches were used to identify models to explain the variation in occupancy and abundance between patch sites (the genetic algorithm model selection approach and selection of the variables with the largest independent effect identified by HP). There were some differences between the models identified by the two methods, which may be due to the relatively small sample sizes used for the analysis or correlation among the independent variables. The latter may result in the inclusion of one or more terms in the model that best fit the data but do not actually have a direct influence on the dependent variable (MacNally, 2000). A potential example of this is the identification of the term "SlopelRidge" as the third variable in the best model to explain site occupancy. This variable was important to the fit of the model (increasing it from $74 \%$ to $84 \%$ of deviance explained) because it helped explain the observed presence of the study species in two sites that did not match the predictions based only on basal area and distance to the nearest occupied site. The variable itself had a minor independent effect $(1.7 \%)$ and its inclusion and negative coefficient in the model may have been because sites that did not fit this category (i.e. gullies or swamps) were more likely to have some other feature such as high ground cover or fallen logs, which were sometimes adequate to support very small numbers $(<5$ individuals) of agile antechinus. Likewise for the abundance models, the variables relating to proximity to unfragmented habitat and the number and size of logs on the forest floor had low independent contributions but were present in the best model. However, the former has previously been identified as being an important influence on abundance of $A$. agilis in fragmented habitat (Downes et al., 1997; Lindenmayer et al., 1999) and the latter (fallen logs) may provide a source of food (logdwelling invertebrates) and shelter while foraging on the forest floor so that sites with high log counts may provide more resources (Braithwaite, 1979; Cox et al., 2003).

\subsection{Fragmentation effects on sex ratio}

We identified a significant reduction in the adult sex ratio in the remnant sites in the pine plantation relative to the unfragmented sites, suggesting fragmentation has an effect on sex ratio. Dispersal is predominantly by males in A. agilis (Cockburn et al., 1985), and, given that the pine matrix does not provide suitable habitat to 
sustain $A$. agilis populations, it is possible that the pine matrix results in higher dispersal-associated mortality than does native forest, thus contributing to the lower proportion of males in fragmented compared to unfragmented sites. Biased sex ratios due to dispersal-related mortality in fragmented landscapes have been identified in other mammals (Raska-Jurgiel, 1992: female-biased sex ratios in a vole with male-biased dispersal) and birds (Beshkarev et al., 1995; Dale, 2001: male-biased sexratios in birds with female-biased dispersal). Conversely, in a system of connected roadside vegetation remnants (corridors), Downes et al. (1997) found the sex ratio of A. agilis to be male-biased in distant habitat corridors $(>1.5 \mathrm{~km}$ from native forest) relative to corridors adjacent to native forest, and the sex ratio in both corridor types was more male-biased than in 20-80 ha areas of native forest. Similar observations have been reported for two other species. Bank vole (Clethrionomys glareolus) populations, in which dispersal is male-biased (Gliwicz and Ims, 2000), have reduced proportions of females in populations further away from permanently inhabited forest (Van Apeldoorn et al., 1992), and a bird species with female-biased dispersal showed a femalebiased sex ratio in a geographically isolated population (Wegge et al., 1992). It is likely that although dispersal mortality may bias sex-ratios toward the more philopatric sex in fragmented systems, patch populations maintained by immigration (e.g. sink populations) will have sex-ratios biased toward the dispersing sex. We did not detect a significant relationship between estimated population size and sex ratio in the fragmented system, but the only populations with male-biased sex ratios $(n=4)$ had estimated population sizes of less than 10 individuals. This is consistent with the idea that the larger populations are a net source of dispersers whereas the smaller populations are more dependent on immigration for most of their recruitment and are therefore more likely to be male-biased. The effect of habitat fragmentation on sex ratio has consequences for population persistence in that it reduces the effective population size and increases the rate of genetic drift and inbreeding (Mills and Smouse, 1994). However genetic diversity data from this study suggest that this is not a risk to A. agilis in the Tumut plantation system.

\section{Conclusions}

Our results demonstrate that remnant stands of eucalypt forest within the pine plantation provide useful habitat for populations of A. agilis. Although many of the populations were very small (seven of 16 had an estimated size of less than 10 individuals), none showed genetic evidence of being isolated. This finding lends support to the utility of retaining habitat patches in plantation landscapes for wildlife conservation in that it shows that the extant populations are not simply isolated remnants of the species' pre-fragmentation distribution. If that were the case, they may be prone to extinction through factors associated with population isolation, such as loss of genetic diversity or inbreeding (Frankham, 1995b; Lacy, 1997). Demographic model selection and hierarchical partitioning highlighted measures of habitat quality (vegetation basal area) and connectivity (proximity to nearest occupied site) as being the important factors driving the observed patterns of site occupancy in the fragmented system. Population size in the occupied sites appears to be influenced most strongly by forest type, with patch area and landscape context (gully) also having strong effects. Although the extant populations do not appear to be isolated, the strong effect of proximity to an occupied site on the patterns of site occupancy suggests that dispersal distances through the pine plantation are restricted. Whether they are restricted relative to the scale of dispersal events in unfragmented habitat requires further investigation.

In conservation research there is always a compromise between the intensity and scale of the study and the degree of replication possible and a limitation of our study design is that while the fieldwork was replicated extensively within a single fragmented and unfragmented area, we did not replicate the study on a landscape scale (e.g. replication in other plantation and unfragmented landscapes). Although the properties of the pine plantation matrix are unlikely to vary between plantation landscapes, the response of patch populations and the environmental variables identified as being important influences on demography are likely to be influenced by local conditions such as the area, spatial configuration and quality of remnant habitat. For this reason, replication of the study design in other plantation landscapes may improve our ability to make generalisations about the impacts of fragmentation due to softwood plantation establishment on native fauna.

If large areas of south-eastern Australia currently used for grazing are converted to pine plantation there will be consequences for the native species persisting in remnants of habitat in these landscapes. Other studies of Antechinus spp. in south-eastern Australian fragmented landscapes with a different matrix (usually cleared grazing land) have found that these species can use remnant habitat patches (Dunstan and Fox, 1996; Downes et al., 1997; Knight and Fox, 2000; Cox et al., 2003). Our results suggest that the connectivity of populations residing in such remnants would not be compromised by the conversion of the matrix from pasture to plantation. However, given the presence of large areas of unfragmented habitat adjacent to the pine plantation study area, important follow-up questions are: 1/ How self-sustaining are the patch populations? And 2/ How dependent are the patch populations on immigra- 
tion from adjacent areas of unfragmented habitat for their long-term persistence?

\section{Acknowledgements}

Jim Thompson (Australian Centre for Biodiversity, School of Biological Sciences, Monash University) carried out the model selection analyses presented in this paper. Chris MacGregor and David Rawlins are thanked for their hospitality and assistance with fieldwork at Tumut. Thanks to Rod Peakall, Maxine Piggott and two anonymous reviewers for comments that improved earlier versions of the manuscript. This research was funded by the Marsupial CRC and an Australian Research Council Discovery grant. The fieldwork was carried out under Monash University Animal Ethics permit BSCI/2001/10 and New South Wales National Parks and Wildlife Service research permits B2293 (S.B.) and A2993 (A.T.). This is publication number 76 from the Australian Centre for Biodiversity: Analysis, Policy and Management at Monash University.

\section{Appendix A. Easypop simulation parameters}

\section{A.1. Microsatellite loci}

Simulations included males and females using 2002 estimated population sizes and sex ratios.

Number of loci: 15

Number of possible allelic states per locus: 20

Initial variability: Maximum (each individual's genotype randomly drawn from the possible allelic states)

Mutation rate: 0.002 (range: $10^{-2}-10^{-5}$ )

Mutation model: 97\% single-step mutations, 3\% KAM model (can mutate to any possible allelic state within the accepted range)

Migration scheme:

Generations 1-25: 95\% male migration, 60\% female migration, mean migration distance $3000 \mathrm{~m}$.

Generations 26-75 (final number of generations varied between sites): Zero migration rate for both sexes.

\section{A.2. Mitochondrial locus}

Simulations included females only using estimated 2002 population sizes.

Number of loci: 1

Number of possible allelic states: 20

Initial variability: Maximum (each individual's genotype randomly drawn from the possible allelic states)

Mutation rate: 0.01 (range: $2 \times 10^{-2}-5 \times 10^{-4}$ )

Mutation model: KAM
Migration scheme:

Generations 1-25: 60\% female migration, mean migration distance $3000 \mathrm{~m}$.

Generations 26-75 (final number of generations varied between sites): Zero migration rate.

\section{A.3. Assumptions}

It was assumed that population sizes and sex ratios were constant between generations. Although unrealistic, population sizes in 2002 were high relative to trapping done at some of the same sites in other years so this assumption should result in a conservative answer. The mutation rate assumptions affected the equilibrium levels of genetic variation in the last few generations of the simulations. The ones we have used here are conservative.

\section{References}

Ball, S.J., Lindenmayer, D.B., Possingham, H.P., 2003. The predictive accuracy of population viability analysis: a test using data from two small mammal species in a fragmented landscape. Biodiversity and Conservation 12, 2393-2413.

Balloux, F., 2001. EASYPOP (version 1.7): A computer program for the simulation of population genetics. Journal of Heredity 92, 301302 .

Bentley, J.M., Catterall, C.P., Smith, G.C., 2000. Effects of fragmentation of araucarian vine forest on small mammal communities. Conservation Biology 14, 1075-1087.

Beshkarev, A.B., Blagovidov, A., Sokolski, S., Hjeljord, O., 1995. Populations of capercaillie and hazel grouse in large natural and logged forest in northern Russia. In: Proceedings of the International Grouse Symposium 1950-1992, pp. 12-18.

Braithwaite, R.W., 1979. Social dominance and habitat utilization in Antechinus stuartii. Australian Journal of Zoology 27, 517-528.

Brouat, C., Sennedot, F., Audiot, P., Leblois, R., Rasplus, J.-Y., 2003. Fine-scale genetic structure of two carabid species with contrasted levels of habitat specialization. Molecular Ecology 12, 1731-1745.

Burnham, K.P., Overton, W.S., 1978. Estimation of the size of a closed population when capture probabilities vary among animals. Biometrika 65, 625-633.

Campbell, N.J.H., Harris, F.C., Elphinstone, M.S., Baverstock, P.R., 1995. Outgroup heteroduplex analysis using temperature gradient gel electrophoresis: high resolution, large scale, screening of DNA variation in the mitochondrial control region. Molecular Ecology 4, 407-418.

Chevan, A., Sutherland, M., 1991. Hierarchical partitioning. The American Statistician 45, 90-96.

Cockburn, A., Lazenby-Cohen, K.A., 1992. Use of nest trees by Antechinus stuartii, a semelparous lekking marsupial. Journal of Zoology, London 226, 657-680.

Cockburn, A., Scott, M.P., Scotts, D.J., 1985. Inbreeding avoidance and male-biased natal dispersal in Antechinus spp. (Marsupialia, Dasyuridae). Animal Behaviour 33, 908-915.

Cox, M.P., Dickman, C.R., Hunter, J., 2003. Effects of rainforest fragmentation on non-flying mammals in the Eastern Dorrigo Plateau, Australia. Biological Conservation 115, 175-189.

Craig, J.L., Mitchell, N., Saunders, D.A., 2000. Conservation in Production Environments: Managing the Matrix. Surrey Beatty and Sons, Chipping Norton. 
Crowther, M.S., Sumner, J., Dickman, C.R., 2003. Speciation of Antechinus stuartii and A. subtropicus (Marsupialia: Dasyuridae) in eastern Australia: molecular and morphological evidence. Australian Journal of Zoology 51, 443-462.

Dale, S., 2001. Female-biased dispersal, low female recruitment, unpaired males, and the extinction of small isolated bird populations. Oikos 92, 344-356.

Debinski, D.M., Holt, R.D., 2000. A survey and overview of habitat fragmentation experiments. Conservation Biology 14, 342-355.

Department of Primary Industries and Energy, 1997. Plantations for Australia: The 2020 Vision. Joint Report from Ministerial Council on Forestry, Fisheries and Aquaculture, Standing Committee on Forestry, Plantations Australia, Australian Forest Growers, National Association of Forest Industries. Department of Primary Industries and Energy, Canberra.

Dickman, C.R., 1980. Ecological studies of Antechinus stuartii and Antechinus flavipes (Marsupialia: Dasyuridae) in open-forest and woodland habitats. Australian Zoologist 20, 433-446.

Dickman, C.R., Parnaby, H.E., Crowther, M.S., King, D.H., 1998. Antechinus agilis (Marsupialia: Dasyuridae), a new species from the A. stuartiicomplex in south-eastern Australia. Australian Journal of Zoology 46, 1-26.

Downes, S.J., Handasyde, K.A., Elgar, M.A., 1997. The use of corridors by mammals in fragmented Australian eucalypt forests. Conservation Biology 11, 718-726.

Driscoll, D.A., 2004. Extinction and outbreaks accompany fragmentation of a reptile community. Ecological Applications 14, 220-240.

Dunstan, C.E., Fox, B.J., 1996. The effects of fragmentation and disturbance of rainforest on ground-dwelling small mammals on the Roberston Plateau, New South Wales, Australia. Journal of Biogeography 23, 187-201.

El Mousadik, A., Petit, R.J., 1996. High level of genetic differentiation for allelic richness among populations of the argan tree [Argania spinosa (L.) Skeels] endemic of Morocco. Theoretical and Applied Genetics 92, 832-839.

Fahrig, L., 2001. How much habitat is enough. Biological Conservation 100, 65-74.

Fleishman, E., Thomson, J.R., MacNally, R., Murphy, D.D., Fay, J.P., 2004. Predicting species richness of multiple taxonomic groups using indicator species. Conservation Biology, in press.

Frankham, R., 1995a. Effective population size/adult population size ratios in wildlife - a review. Genetical Research 66, 95-107.

Frankham, R., 1995b. Conservation Genetics. Annual Review of Genetics 29, 305-327.

Gliwicz, J., Ims, R.A., 2000. Dispersal in the bank vole. Polish Journal of Ecology 48, S51-S61.

Goudet, J., 1995. FSTAT (vers. 1.2): a computer program to calculate F-statistics. Journal of Heredity 86, 485-486.

Hall, S., 1980. Diel activity of three small mammals coexisting in forest in Southern Victoria. Australian Mammalogy 3, 67-79.

Hanski, I., 1994. A practical model of metapopulation dynamics. Journal of Animal Ecology 63, 151-162.

Hitchings, S.P., Beebee, T.J.C., 1998. Loss of genetic diversity and fitness in common toad (Bufo bufo) populations isolated by inimical habitat. Journal of Evolutionary Biology 11, 269-293.

Hood, G.M., 2004. PopTools version 2.6.2. Available on the internet. URL http://www.cse.csiro.au/poptools.

Keller, I., Largiader, C.R., 2003. Recent habitat fragmentation caused by major roads leads to reduction of gene flow and loss of genetic variability in ground beetles. Proceedings of the Royal Society of London, Series B 270, 417-423.

Knight, E.H., Fox, B.J., 2000. Does habitat structure mediate the effects of forest fragmentation and human-induced disturbance on the abundance of Antechinus stuartii?. Australian Journal of Zoology 48, 577-595.

Kraaijevelt-Smit, F.J.L., Ward, S.J., Temple-Smith, P.D., $2002 \mathrm{a}$. Multiple paternity in a field population of a small carnivorous marsupial, the agile antechinus, Antechinus agilis. Behavioural Ecology and Sociobiology 52, 84-91.

Kraaijeveld-Smit, F.J.L., Ward, S.J., Temple-Smith, P.D., Paetkau, D., 2002b. Factors influencing paternity success in Antechinus agilis: last-male sperm precedence, timing of mating and genetic compatibility. Journal of Evolutionary Biology 15, 100-107.

Lacy, R.C., 1997. Importance of genetic variation to the viability of mammalian populations. Journal of Mammalogy 78, 320-335.

Lazenby-Cohen, K.A., Cockburn, A., 1991. Social and foraging components of the home range in Antechinus stuartii (Dasyuridae: Marsupialia). Australian Journal of Ecology 16, 301-307.

Lindenmayer, D.B., Cunningham, R.B., Pope, M.L., 1999. A largescale experiment to examine the effects of landscape context and habitat fragmentation on mammals. Biological Conservation 88, $387-403$.

Lindenmayer, D.B., Cunningham, R.B., Pope, M.L., Gibbons, P., Donnelly, C.F., 2000. Cavity sizes and types in Australian eucalypts from wet and dry forest types: A simple of rule of thumb for estimating size and number of cavities. Forest Ecology \& Management 137, 139-150.

Lindenmayer, D.B., Franklin, J.F., 2002. Conserving Forest Biodiversity: A Comprehensive Multiscaled Approach. Island Press, Washington.

Lindenmayer, D.B., Lacy, R.C., 2001. Small mammals, habitat patches and PVA models: a field test of model predictive ability. Biological Conservation 103, 247-265.

Lindenmayer, D.B., McCarthy, M.A., 2001. The spatial distribution of non-native plant invaders in a pine-eucalypt landscape mosaic in south-eastern Australia. Biological Conservation 102, 77-87.

Lindenmayer, D.B., Peakall, R., 2000. The Tumut experiment integrating demographic and genetic studies to unravel fragmentation effects. In: Young, A.G., Clarke, G.M. (Eds.), Demography and Viability of Fragmented Populations. Cambridge University Press, New York, pp. 173-201.

Lunney, D., Matthews, A., Grigg, J., 2001. The diet of Antechinus agilis and A. swainsonii in unlogged and regenerating sites in Mumbulla State Forest, south-eastern New South Wales. Wildlife Research 28, 459-464.

MacArthur, R.H., Wilson, E.O., 1963. An equilibrium theory of insular biogeography. Evolution 17, 373-383.

MacKenzie, D.I., Nichols, J.D., Lachman, G.B., Droege, S., Royle, J.A., Langtimm, C.A., 2002. Estimating site occupancy rates when detection probabilities are less than one. Ecology 83, 2248-2255.

MacNally, R., 2000. Regression and model-building in conservation biology, biogeography and ecology: the distinction between - and reconciliation of - 'predictive' and 'explanatory' models. Biodiversity and Conservation 9, 655-671.

Mech, S.H., Hallett, J.G., 2001. Evaluating the effectiveness of corridors: a genetic approach. Conservation Biology 15, 467-474.

Mills, L.S., Smouse, P.E., 1994. Demographic consequences of inbreeding in remnant populations. The American Naturalist 144, $412-431$.

Otis, D.L., Burnham, K.P., White, G.C., Anderson, D.R., 1978. Statistical inference from capture data on closed animal populations. Wildlife Monographs, 62.

Paetkau, D., 1999. Microsatellites obtained using strand extension: an enrichment protocol. Biotechniques 26, 690-697.

Petit, R.J., El Mousadik, A., Pons, O., 1998. Identifying populations for conservation on the basis of genetic markers. Conservation Biology 12, 844-855.

Raska-Jurgiel, E., 1992. Demography of woodland rodents in fragmented habitat. Acta Theriologica 37, 73-90.

Raymond, M., Rousset, F., 1995. GENEPOP (version 1.2): population genetics software for exact tests and ecumenicism. Journal of Heredity 86, 248-249.

Ricketts, T.H., 2001. The matrix matters: effective isolation in fragmented landscapes. The American Naturalist 158, 87-99. 
Saunders, D.A., Hobbs, R.J., Ehrich, P.R., 1993. Nature Conservation 3. The Reconstruction of Fragmented Ecosystems. Surrey Beatty \& Sons, Chipping Norton.

Saunders, D.A., Hobbs, R.J., Margules, C.R., 1991. Biological consequences of ecosystem fragmentation: a review. Conservation Biology 5, 18-32.

Srikwan, S., Woodruff, D., 2000. Genetic erosion in isolated smallmammal populations following rainforest fragmentation. In: Young, A.G., Clarke, G.M. (Eds.), Demography and Viability of Fragmented Populations. Cambridge University Press, New York, pp. 149-172.

Stacey, P.B., Taper, R., 1992. Environmental variation and the persistence of small populations. Ecological Applications 2, 18-29.

State of the Environment Advisory Council, 2001. Australia: State of the Environment 2001. CSIRO Publishing, Collingwood.

Steinberg, E.K., Jordan, C.E., 1997. Using molecular genetics to learn about the ecology of threatened species: The allure and illusion of measuring genetic structure in natural populations. In: Fiedler, P.L., Kareiva, P.M. (Eds.), Conservation Biology for the Coming Decade. Chapman \& Hall, New York, pp. 440-460.

Stow, A.J., Sunnucks, P., Briscoe, D.A., Gardner, M.G., 2001. The impact of habitat fragmentation on dispersal of Cunningham's skink (Egernia cunninghamii): evidence from allelic and genotypic analyses of microsatellites. Molecular Ecology 10, 867-878.

Suckling, G.C., Heislers, A., 1978. Populations of four small mammals in radiata pine plantations and eucalypt forest of north-eastern Victoria. Australian Wildlife Research 5, 305-315.

Sumner, J.M., Dickman, C.R., 1998. Distribution and identity of species in the Antechinus stuartii-A. flavipes group (Marsupialia: Dasyuridae) in south-eastern Australia. Australian Journal of Zoology 46, 27-41.

Sunnucks, P., Hales, D., 1996. Numerous transposed sequences of mitochondrial cytochrome-oxidase I-II in aphids of the genus Sitobion (Hemiptera, Aphididae). Molecular Biology and Evolution $13,510-524$
Sunnucks, P., Wilson, A.C.C., Beheregaray, L.B., Zenger, K., French, J., Taylor, A.C., 2000. SSCP is not so difficult: the application and utility of single-stranded conformation polymorphism in evolutionary biology and molecular ecology. Molecular Ecology 9, 1699-1710.

Tallmon, D.A., Draheim, H.M., Mills, L.S., Allendorf, F.W., 2002. Insights into recently fragmented vole populations from combined genetic and demographic data. Molecular Ecology 11, 699-709.

Thompson, J.D., Higgins, D.G., Gibson, T.J., 1994. CLUSTAL W: improving the sensitivity of progressive multiple sequence alignment through sequence weighting, positions-specific gap penalties and weight matrix choice. Nucleic Acids Research 22, 46734680.

Van Apeldoorn, R.C., Oostenbrink, W.T., Van Winden, A., Van Der Zee, F.F., 1992. Effects of habitat fragmentation on the bank vole, Clethrionomys glareolus, in an agricultural landscape. Oikos 65, 265-274.

Vucetich, L.M., Vucetich, J.A., Joshi, C.P., Waite, T.A., Peterson, R.O., 2001. Genetic (RAPD) diversity in Peromyscus maniculatus populations in a naturally fragmented landscape. Molecular Ecology 10, 35-40.

Walsh, C., MacNally, R., 2003. The hier.part package. Hierarchical partitioning. R project for statistical computing. Available from: <URL: http://cran.r-project.org>

Wartenberg, D., 1985. Multivariate spatial correlation: a method for exploratory geographical analysis. Geographical Analysis 17, $263-$ 283

Wegge, P.J., Rolstad, J., Gjerde, I., 1992. Effects of boreal forest fragmentation on capercaillie grouse: empirical evidence and management implications. In: McCullough, D.R., Barrett, R.H. (Eds.), Wildlife 2001: Populations. Elsevier Scientific Publishers, New York, pp. 738-749.

Wilson, B.A., Bourne, A.R., Jessop, R.E., 1986. Ecology of small mammals in coastal heathland at Anglesea, Victoria. Australian Wildlife Research 13, 397-406. 